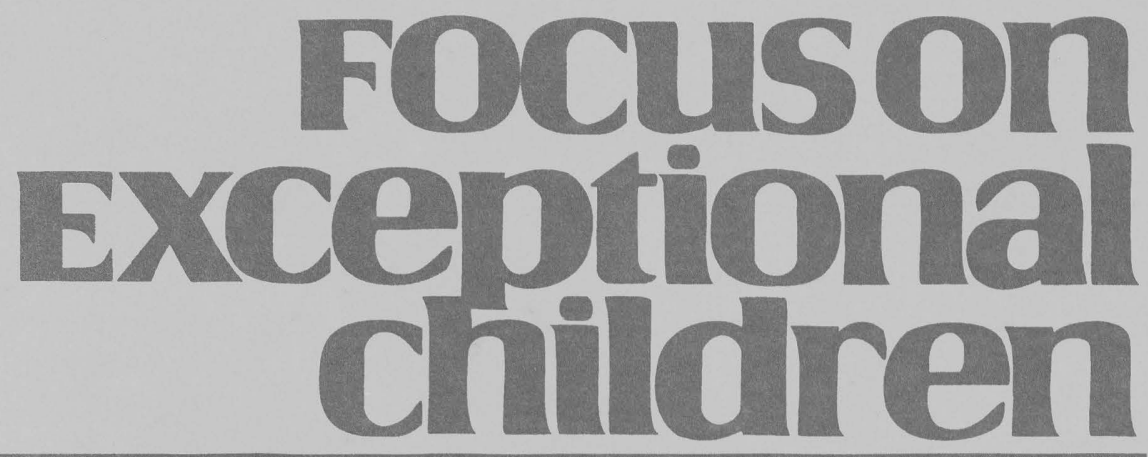

\title{
Children and Youth with Autism Spectrum Disorders: The Search for Effective Methods
}

\author{
Richard L. Simpson
}

The current attention to children and youth with autism spectrum disorders (ASD) is no less than astonishing. Media coverage of ASD clearly illustrates that the increasing and interminably enigmatic conditions of autism and ASD hold strong interest for the general public in addition to the professional community. Television specials, newspaper articles, and magazine feature stories on autism are widespread (see, for example, Newsweek, March 24, 2008; Time, May 15, 2006). That the fashion- and celebrity-focused magazine Town and Country chose to publish an article on autism (Guernsey, 2006), including prevalence data, diagnostic markers, etiology debates, and information on treatment choices, speaks volumes about the extent to which matters related to ASD have captured public interest.

Multiple explanations have been set forth to explain the intense interest in issues and themes connected with ASD. Among these reasons is the increased prevalence of autismrelated disabilities. The Centers for Disease Control and Prevention (2008) has estimated that approximately 1 in 150 children will fall somewhere on the autism spectrum. That prevalence estimate is a dramatic increase over the 4 to 5 per 10,000 estimate of a decade ago (Lotter, 1966).

I clearly recall a conversation with an academic dean in the early stages of my higher education career regarding the advisability of my conducting research on learners with autism. The Dean counseled me not to invest substantial research time and effort with students who have autism, arguing that the disability affected so few individuals that I would have difficulty locating sufficient numbers of subjects to conduct research and that the topic of autism was so esoteric that it would be of interest to only a few individuals.

Obviously, interest in matters pertaining to ASD has grown exponentially. More important, the impact that autism-related disabilities is having on families, schools, and communities is profound. ASD is currently far more common than Down syndrome, juvenile diabetes, and childhood cancer (Centers for Disease Control and Prevention, 2008); thus, it is particularized, and the aggregate impact is profound (Simpson \& Myles, 2008).

Dr. Simpson is with the Department of Special Education at the University of Kansas. 
Another reason for the extensive and far-reaching interest in ASD is the disability's legacy of mystery and controversy. Bluntly speaking, children and youth with ASD are eminently unique and the enigmatic behavioral elements that comprise autism often seem to make individuals with this disability-even when compared to other exceptional groups-an inexplicable and baffling group. Without a doubt, those who are familiar with children and youth with autism-related challenges learn to appreciate and expect a wide range of abilities and needs. Some individuals diagnosed with ASD have average or above-average abilities, and a small percentage of them are gifted. In contrast, others diagnosed with ASD have significant intellectual and communication challenges.

Variable perceptions and raucous disputes over the cognitive abilities of individuals with ASD and the general mystery of autism can also be attributed to accounts of those with ASD having extraordinary isolated abilities and remarkable splinter skills. Virtually all persons diagnosed with an ASD can be expected to have co-morbid conditions

\section{FOCuson Exceptional children}

ISSN 0015-511X FOCUS ON EXCEPTIONAL CHILDREN (USPS 203-360) is published monthly except June, July, and August as a service to teachers, special educators, curriculum specialists, administrators, and those concerned with the special education of exceptional children. This publication is annotated and indexed by the ERIC Clearinghouse on Handicapped and Gifted Children for publication in the monthly Current Index to Journals in Education (CIJE) and the quarterly index, Exceptional Children Education Resources (ECER). The full text of Focus on Exceptional Children is also available in the electronic versions of the Education Index. It is also available in microfilm from Serials Acquisitions, National Archive Publishing Company, P.O. Box 998, Ann Arbor, MI 48106-0998. Subscription rates: individual, \$42 per year; institutions, \$56 per year. Copyright @ 2008 , Love Publishing Company. All rights reserved. Reproduction in whole or part without written permission is prohibited. Printed in the United States of America. Periodical postage is paid at Denver, Colorado. POSTMASTER: Send address changes to:

Love Publishing Company

Executive and Editorial Office P.O. Box 22353

Denver, Colorado 80222

Telephone (303) 221-7333

\section{EDITORIAL BOARD}

Lisa Dieker

University of Central Florida
Paula Maccini University of Maryland

Marleen Pugach

University of Wisconsin-Milwaukee

Carrie E. Watterson Editor
Stanley F. Love Publisher (e.g., obsessive compulsive disorders, seizure disorders, attention-deficit/hyperactivity disorder, and self-injurious behavior), further intensifying the inscrutable nature, complexity, and challenges connected with ASD. Finally, families and professionals alike commonly believe that the peculiarities and clinical characteristics of ASD conceal and obscure the underlying true abilities and potential of individuals diagnosed with autism-related conditions.

Widely circulated debates over the causes of ASD are legendary. To be sure, long-term and vociferous ASD etiology debates-which show no signs of ending any time soon-have dramatically accelerated controversy within the ASD community and beyond. Although exact causes remain unknown, there is no shortage of opinion and speculation about the reasons and driving forces behind autism. Environmental agents such as mercury, vaccinations, and drugs have long been debated as possible causes of autism (Waly et al., 2004).

The Centers for Disease Control and Prevention (2008) and many professionals have dismissed childhood vaccinations as a cause for all but a handful of cases of autism. Nevertheless, strident debate continues over the connection between vaccinations and ASD. A recently published study (Young, Grier \& Grier, 2008) used the automated Vaccine Safety Datalink maintained by the Centers for Disease Control and Prevention (CDC) to make a connection between mercury from the Thimerosal used in vaccines and autism and other neurodevelopmental disorders. That the CDC data base was allegedly unavailable to researchers until federal legislation opened the files further energizes and exacerbates conspiracy contentions that national resources and special-interest groups have orchestrated efforts to conceal the role of vaccines and other environmental agents as a cause of ASD.

A salient and predictable outcome of the enigmatic patterns associated with ASD, multiple controversies, and the variable perceptions about individuals with ASD has been the debate over which treatments, interventions, methods, and educational procedures hold the most promise (Biklen, 1993; Iovannone et al., 2003; Simpson, 2005; Volkmar, Cook \& Pomeroy, 1999). Indeed, there has been vociferous discussion about the logic, rationale, supporting evidence, and appropriateness of various methods, educational strategies, and treatments for learners with ASD (Gresham, Beebe-Frankenberger, \& MacMillan, 1999; National Research Council, 2001).

The popular press has participated in these heated discussions, fueling the fires of controversy. An illustration of this claim is found in a Time magazine cover story on ASD (Wallis, 2006). The article critiqued intervention and treatments for children and youth identified as having ASD. Readers of this widely circulated magazine were told that 
the controversial and generally discounted method-facilitated communication (Biklen, 1993) - could produce positive outcomes for persons with autism. In actuality, multiple scientific and empirically based studies have clearly shown that facilitated communication lacks efficacy and has generally had a negative impact on learners with ASD (Simpson \& Myles, 1995; Wheeler et al., 1993).

Wallis (2006), who authored the article, acknowledged that facilitated communication is a controversial technique that is often shunned. Nevertheless, facilitated communication was generally described as an effective method: "[Facilitated communication] clearly turned Hannah's life around. Since her breakthrough, she no longer spends much of her day watching Sesame Street and Blue's Clues. Instead, she is working her way through high school biology, algebra and ancient history" (p. 44).

Another example of media attention to ASD-related controversial intervention and educational-method information is an article in the popular magazine Forbes (Hardy, 2008). The feature article described a school in Atlanta that serves learners with a variety of neurological disorders and autism. The program uses "intensive sensory and motor-skills training to help the brain build and strengthen neural pathways" (p. 54). The controversial nature of the program's methodology was noted in that

\footnotetext{
[It] has never been subjected to an unbiased clinical trial or peer-reviewed by a medical journal. Nor have her results been replicated by others. On those scores it is not different from discredited autism therapies such as chelation, listening to Mozart, gluten-free diets and swimming with dolphins. (p. 54)
}

The article's author added, " $\ldots$ but there is evidence that the theory underlying O'Dell's therapy has some scientific validity" (p. 54). Unfortunately, the supporting evidence for the program was not discussed.

Interestingly, the Forbes article was disseminated by the influential professional organization Council for Exceptional Children through its online newsletter (CEC SmartBrief, 2008). The CEC's description of the program's methodology was that it has "not been proven in clinical trials" (p. 1). Yet, the article went on to say that it has "shown some scientific validity" (p. 1). Once more, the supporting scientific evidence and validity for the program was not provided, leaving CEC members to draw their own conclusions and inferences about the nature and precise effectiveness of the method or simply take the word of CEC that the O'Dell therapy program was efficacious.

So what is the import of the ubiquitous musings of journalists, along with the additional flood of variable and often unsupported information about ASD? The simple answer is that parents and family members, professionals, policy makers, and the general public consistently and routinely receive confusing, mixed, and erroneous information about ASD and autism-related matters. This steady diet of mixed and confusing information has made it difficult for professionals and others to accurately understand ASD and its myriad issues, including strategies and methods to successfully address the needs of learners identified as having an autismlinked disability. Without a doubt, accurate and reliable information is sine qua non for developing effective micro and macro plans for responding to the needs of individuals with ASD and their families.

Of course, the phenomenon of a rush of inconsistent and spurious information occurs whenever a significant medical or disability trend surfaces. For example, at the height of the polio epidemic of the 1950s, there was a flood of inaccurate and unreliable information and treatment and preventive recommendations. Until an accurate and reliable scientific understanding of the nature and cause of polio was found and effective preventive and treatment programs were available, the public and medical professionals alike were overwhelmed by inaccurate information and ineffective treatments. When considered in this context, the current variable opinions and vetting about ASD matters by popular press journalists and professionals are in and of themselves expected-and no more than attempts to grapple with a pernicious and ever-increasing disability.

One might even argue that these ruminations are of little consequence relative to understanding, identifying, and appropriately using maximally efficacious methods with learners who have ASD. Or, most optimistically, the incessant musings of writers about autism-related matters might be perceived positively because they draw attention to ASD that translates into research, policy, and other constructive actions.

To be fair, the impact of speculative, capricious, and unreliable information on the current state of autism knowledge is difficult to judge. Notwithstanding this concession, variable and often incorrect information illustrates a significant lack of understanding about ASD issues and challenges, as well as significant disagreement about which treatments and interventions bode best for persons identified with autism-related disabilities. Undeniably, parents and families, professionals, policy makers, and the general public are being stymied by a lack of reliable information regarding the utility and suitability of purported treatments and interventions for learners with ASD. Moreover, the lack of practical information and well-designed guidelines that professionals and families can use to identify the most suitable, effective, and utilitarian methods from among the countless available interventions and treatments that portend the best outcomes for learners with ASD only serves to intensify and further polarize variable opinions and perspectives concerning autism. 
Within the context of these circumstances, this article explores themes and concerns that are linked to identifying and adopting the most effective, practical, and cost-efficient practices and strategies for children and youth with ASD. Basic elements that form the foundation of an effective program for learners identified with ASD are suggested for facilitating widescale program improvements.

\section{IDENTIFYING EFFECTIVE PRACTICES FOR CHILDREN AND YOUTH WITH ASD}

Debates and discussions connected to defining, vetting, and adopting effective strategies and practices with children and youth with ASD plainly reveal the strong belief that learners with autism-related challenges require specialized treatments and interventions. Independent of specific positions among ASD stakeholders regarding which methods are most effective and suitable for individual students with ASD is the agreed-upon conviction that persons with ASD achieve desired outcomes as a function of exposure to specialized tools implemented by ASD specialists.

Indeed, rarely would one encounter a family member connected to a person with ASD or a professional who works with children or adolescents with ASD who would contend that the unique learning and support needs of students with ASD can be addressed satisfactorily using exclusively generic disability techniques and strategies. Thus, the issue among ASD stakeholders is not whether students with ASD require specialized practices, interventions, and treatments but, rather, which of the specialized methods developed for children and adolescents with autism-related disabilities are the most efficient, effective, and suitable.

Needless to say, issues connected to effective educational practices have not been limited to students with ASD, or even students with special needs, for that matter. The topic of identifying and adopting effective practice is a central feature in current school reform efforts, and prominent in current educational literature (Christie, 2008). Use of effective methods undoubtedly is a critical underpinning of current education legislation. The No Child Left Behind Act (2001) and the Individuals with Disabilities Education Improvement Act of 2004 (IDEA) both recommend that educators use effective educational practices based on scientifically based research (SBR).

As a consequence, all sectors and facets of education have been affected by attempts and movements to bring a more scientific and objective orientation to choosing educational methodology and practices. Nevertheless, relative to the trends and policies focused on using objectively evaluated tools, interventions and treatments for learners with ASD are unique. This distinctive role is a function of the inimitable nature of children and youth with ASD and to the field's long legacy of tolerating, accepting, and advancing methods and strategies that lack utility and efficacy (Gresham, Beebe-Frankenberger, \& MacMillan, 1999; Simpson, 2005).

Various vocations, businesses, and professions debate and wrestle with the knotty issues of vetting various purported interventions and methods and deciding from among the various alternatives those that are most suitable and utilitarian. A prototypical example is the field of self-improvement. As any casual television watcher or magazine reader can attest, countless unproven and ineffective products are advertised, purporting to enhance one's attractiveness with little or no effort; and easy weight-loss methods and unrealistic health gains permeate the media.

Within the disability field, ASD is particularly noteworthy for its gullibility and credulity in accepting and tolerating unproven and ineffective interventions and treatments and for failing to assist professionals, families and policy makers in identifying the most effective and utilitarian methods. To be sure, the ASD field is desperate for answers and solutions, thus perhaps explaining the field's wellknown and enduring legacy of allowing and supporting unproven and controversial interventions and treatments. This liberal tolerance for novel interventions and treatments is recognized as a strategy that may increase the probability of finding significantly improved methods or perhaps even "the cure" for ASD.

Included among the unverified options for children and adolescents diagnosed with ASD are methods and strategies that purportedly result in acquisition of knowledge and skills that radically exceed learners' perceived abilities and progress achieved through better-understood methods, including recognized effective-practices (Heflin \& Simpson, 1998a; Volkmar, Cook, \& Pomeroy, 1999). A number of these untested methods are linked to assertions that rapid and dramatic improvements and even recovery from ASD are possible (Romanczyk \& Gillis, 2005; Simpson, Myles \& Ganz, 2008).

We can easily understand the charm and appeal of interventions and treatments that promise gains and progress that far exceed more proven and conservative approaches. (In this context, conservative is a reference to practices that have shown efficacy based on traditional evaluations; these methods are often recognized as mainstream strategies). Novel and unproven strategies often fit well with notions that children and youth with ASD comprise a mysterious group that possesses myriad untapped potential and whose so-called disabilities are largely unexplained sets of anomalous characteristics and unsolved puzzles. Unproven and highly hyped approaches may empower families and professionals by offering hope for children's improvement that challenges the belief that autism and autism-related 
disabilities are lifelong disabilities for which there are no cures and no easy answers.

That the field of ASD currently offers neither a definitive explanation for the cause or causes of ASD nor a universally acknowledged best course of treatment serves only to accelerate stakeholders' willingness to gamble on the chance that one of the omnipresent unproven methods may hold the long-awaited key to significant progress and an avenue out of the oft-described bleak and harsh realities of ASD.

Writing in a 2005 Newsweek article on autism, Kalb (2005) poignantly describes a family's search for effective treatments:

Since their sons were diagnosed [with autism], both at age 2, Barry and Dana Craven have tried a dizzying array of therapies: neurofeedback, music therapy, swimming with dolphins, social-skills therapy, gluten-free diets, vitamins, anti-anxiety pills and steroids. (p. 45)

One evident and logical course of action for responding to the widespread use of unproven ASD methods is to advance the process of identifying evidence-based practices and, subsequent to this identification process, require that public school personnel and other public agencies adopt and correctly use these methods. Of course, this mandate exists already through the scientifically based research (SBR) provisions of the No Child Left Behind Act, in which SBR is defined as

...research that involves the application of rigorous, systematic, and objective procedures to obtain reliable and valid knowledge relevant to education activities and programs. (NCLB, 2001)

NCLB thus identifies effective SBR practices as those that have met rigorous vetting standards and that have reliably shown the capacity to produce positive results when used correctly.

The Education Sciences Reform Act of 2002 established the Institute of Education Sciences (IES) within the U.S. Department of Education. IES then set forth an agenda to clarify and streamline definitions and evaluation methods connected to evidence-based practices in education (Institute of Education Sciences, 2008). These steps have arguably led to some improvements in identifying evidencebased educational methods, but in spite of the logic supporting the guiding principles connected to more clearly identifying effective practices and the work of federal and state leaders to facilitate this process, the struggle has seen only modest gains. Several basic and Herculean barriers seem to be primarily responsible for this slow progress.

First and foremost, there is significant lack of agreement regarding the strategies and methods that are most effective and suitable for children and youth with ASD. To be sure, there is intense disagreement on this subject, and this lack of concurrence shows no signs of abating any time soon! A number of methods and strategies for students with ASD have advocates who passionately embrace and support specific approaches with nearly religious fervor and commitment, exasperating the aim of reaching accord on the approaches that are most acceptable and efficacious.

Even when a purely scientific and purportedly objective strategy is used to reach decisions about the relative efficacy of ASD interventions and treatments, significant questions and issues and a lack of consensus remain regarding how best to identify and evaluate scientifically valid practices (U.S. Department of Education, 2003). For instance, in reference to using a science-based strategy to identify evidence-based methods, Odom et al. (2005) observed that "the "devil is in the details"' (p. 137).

Second, strong evidence, policy backing, and common sense support the need for a variety of effective methods and strategies for children and youth with ASD. Undeniably, no single approach or strategy will always be most effective with all learners with ASD. Clearly, the variable needs and heterogeneous characteristics of students with ASD require different approaches. The salient caveat is that these practices must be matched carefully to individuals' unique requirements, and that they must have demonstrated objectively the capability of producing substantial positive outcomes when used with fidelity.

Third, as noted earlier, the very meaning and nature of the makeup and salient elements of an effective practice are unsettled and subject to significantly variable standards and interpretations. NCLB advocates for effective practices in which the strategies, methods, and materials have been validated using research designs employing random samples and control and experimental groups. For a variety of reasons, this model of research is uncommon in educational research involving learners with ASD; thus, to render judgments of scientific validity based on this method is often useless, and the conundrum of the nature of effective methods is even more confusing. This is indicated in that there are virtually no listings of scientifically valid methods for children and youth with ASD on the U.S. Department of Education's Institute of Educational Sciences What Works Clearinghouse website (http://ies.ed.gov/ncee/wwc/). In contrast to the neatly gauged interpretation of the Institute of Educational Sciences are the highly variable, idiosyncratic, and pragmatic standards for effective methods used by many teachers and parents.

On numerous occasions I have encountered teachers, related-services professionals, and parents who argue that they are uniquely qualified to subjectively understand the distinctive needs of individual children and youth. They contend that they are able to match methods with learners' needs and learning styles. Thus, independent of scientific 
validation findings using traditional methods, these stakeholders passionately contend that they are best able to evaluate various ASD treatments and interventions using undefined criteria, and to use these ambiguous and indefinable standards in choosing methods that bode best for desired student outcomes.

The vetting extremes of relying on narrowly defined, highly conservative methods and informal and vague approaches to gauge the effectiveness of ASD interventions and treatments visibly illustrate the range of ways that can be used to determine the utility of a method. Plainly, when used exclusively, neither extreme is a satisfactory option for addressing this all-important matter. Without argument, professionals and parents have an obvious need for a practical and straightforward decision-making process for identifying effective methods for individual students with ASD. This requires a foundation of science in combination with particularized student and family considerations.

At the end of the day, teams of professionals and family members must jointly make a determination about what methods have the best chance of being effective with given children and families in distinct educational settings. Some might argue that intervention and treatment selection is the domain and right of professionals and that parents, families, and other stakeholders are entitled to little more than tacit participation and support of professionals' methodology decisions. In my estimation, this perspective is cavalier, misguided, and rife with problems and poor outcomes for learners with ASD.

Indeed, the successful identification and implementation of utilitarian and practical strategies and practices undoubtedly are best made cooperatively at the local level by groups of informed professionals and parents. These stakeholders have the most knowledge and information about individual students and the unique elements of their educational and family circumstances. Yet, those groups of stakeholders, even if highly motivated and collaboratively-minded, will not be successful in their pursuit without structure and guidance. Professionals, parents, and family members involved in the decision making must be instructed in how to choose, implement, and evaluate effective intervention methods for children and youth with ASD.

This treatment and intervention decision-making process encompasses consideration of straightforwardly described and practical, current, well founded, and authoritative information that professionals and parents can use to make informed judgments about the efficacy and suitability of various methods with specific students. Of course, anyone who has ever attempted to search for ASD efficacy information can attest that it is anything but readily available, practical, and easy to consume! Yet, some improvements are being made on this front. For instance, the National Research
Council's (2001) Committee on Educational Interventions for Children with Autism has identified basic elements needed for all educational programs serving young children with ASD. Another example of this movement is the work of Simpson and colleagues (2005), who categorized and evaluated commonly used interventions and treatments for students with ASD. The five categories they used to evaluate methods were:

1. interpersonal relationship,

2. skill-based,

3. cognitive,

4. physiological/biological/neurological, and

5. other.

Using these classification areas, 33 ASD intervention and treatment methods were evaluated according to the following features:

- outcomes and effects associated with the methods;

- qualifications of persons implementing the intervention or treatment;

- how, where, and when the intervention or treatment is best used;

- potential risks associated with applying the intervention or treatment;

- costs connected to using the intervention or treatment; and

- methods for evaluating each method's effectiveness.

These variables were used to classify the assessed methods as: (a) scientifically based, (b) promising practice, (c) practice having limited supporting information, or (d) not recommended. Scientifically based practices were those having "significant and convincing empirical efficacy and support" (p. 9). Promising practices were methods that had "efficacy and utility with individuals with ASD" (p. 9), albeit additional objective verification was required. Practices with limited supporting information were judged to lack objective and convincing supporting evidence, yet they possibly had potential efficacy and utility. The classification not recommended was used for interventions and treatments that were judged to lack effectiveness and that had the potential to be harmful. Applied behavior analysis (Sturmey, 2008), discrete trial training (deBoer, 2007), pivotal response training (Koegel, Carter \& Koegel, 2003), and Learning Experiences: An Alternative Program for Preschoolers and Parents (LEAP; Strain \& Hoyson, 2000) were evaluated as scientifically based practices.

Although the initial steps to provide ASD interventions and treatments to consumers are undoubtedly being made, resources clearly are insufficient to assist stakeholders. Moreover, finding the most suitable and effective methods 
for students with ASD requires much more than merely reviewing intervention and treatment options. This first element of this process is obviously essential, but it is not sufficient. Simply having available a list of so-called effective methods for professionals and parents to use without practical and well-designed guidelines to be able to make methodology-related decisions will not yield fully satisfactory outcomes. The professionals and parents and families also require a procedure to assist them in determining the suitability of a method with individual students and families in particular settings. It is also essential that the professionals and parents who are making decisions about which methods are believed to be most appropriate demonstrate a willingness and ability to collaborate and work in partnership.

My colleagues and I, as well as others, have recommended the use of basic guiding questions to facilitate consideration of the diverse perspectives and unique individual needs of stakeholders and learners diagnosed with ASD who are attempting to identify and use effective educational methodologies and practices (Freeman, 1997; Heflin \& Simpson, 1998; National Research Council, 2001; Simpson, 2005; Simpson, deBoer, et al., 2005; Simpson, McKee, et al., 2007). Based on the aforementioned work, the queryfocused markers listed below are offered as guiding considerations to assist stakeholders' deliberate intervention and treatment options for learners with ASD.

1. What are the proven effectiveness credentials of intervention and treatment options being considered, and are these geared to yield outcomes that fit the unique needs of individual students?

2. How will the intervention and treatment options selected for use be evaluated?

3. How well do the recommended interventions and treatments fit an individual learner's unique educational and family circumstances?

Question 1 is a pedigree issue. It directs the attention of stakeholders contemplating the use of a given method to whether it has shown supporting scientific and objective evidence of effectiveness. This item also asks stakeholders to consider the extent to which learners who have been reported to benefit from a given intervention or treatment are similar to the specific student under consideration. As noted previously, there is significant variability related to the interpretation of what is meant by effective, scientifically valid, or evidence-based. Thus, stakeholders have to be willing to discriminate among the methods' credentials, including hyped products whose only supporting evidence consists of slick and creative marketing schemes and legitimate treatments and interventions that may have produced desired outcomes under controlled conditions. This requires that at least some stakeholders have a background and training in understanding underlying properties of the methods under consideration, including their potential utility and underlying scientific support.

As earlier noted, multiple mechanisms have been used to validate the efficacy of interventions and treatments for students with ASD. These methods, however, share requirements that each is measured objectively using accepted scientific standards, and that each method has demonstrated the ability to produce positive outcomes when used correctly. Although not necessarily the most popular vetting mechanism, peer-reviewed scientific journals are the most solid form of evidence for interventions and treatments. Nonpeer-reviewed materials, such as those found on product websites and in marketing and promotional brochures, are typically shorter and easier to read than journal articles. These features of convenience may make the evaluation documents appealing, yet these sources of support frequently lack the credibility, objectivity, and evenhandedness of more traditional forms of research information such as those found in professional journals.

Supporting evidence and information from a single source that is not supported by other researchers and professionals and information that lacks peer review and empirical validation but, instead, comes primarily from personal testimonials should be avoided or, at the very least, be considered in a guarded and wary fashion. Methods that promise dramatic and universal improvements that far surpass tested strategies should be reviewed with caution and suspicion.

The evaluation process should also include an assessment of the extent to which the outcomes associated with an approach line up with the needs of the individual children and youth under discussion. Regardless of the reported credentials and utility of a method, it may not be suitable if the students with whom it was validated are dissimilar to the student being reviewed.

Finally, stakeholders are urged to consider whether positive outcome reports relate to behavioral targets with clear pivotal importance. Interventions and treatments should be designed to address salient characteristics of ASD—skill acquisition in social interaction, communication, behavioral, academic, independent living, and so forth.

Question 2 concerns the evaluation of interventions and treatments considered or adopted for use. Included in this crucial component of the decision-making process are: (a) What specific targets will be measured as evidence of progress (i.e., words spoken, behaviors emitted, social interactions demonstrated and skills acquired, etc.)? (b) Who will conduct the evaluations and how frequently will the evaluators assess the impact of an intervention? and (c) What criteria will be used to determine if an intervention or treatment should be continued, discontinued or modified? 
The first of these factors is designed to direct stakeholders toward methods that have a history of yielding positive outcomes. This step, however, does not speak to the merits of a method with particular children. Despite the purported benefits of a method and its credentials, it ultimately must be judged in accordance with whether it yields desired outcomes with an individual student. Accordingly, independent of published or reported research findings, the interventions and treatments require regular and objective evaluations, ideally based on empirically verifiable ongoing data collection methods in students' real-world settings.

Question 3 of the decision-facilitator discussion items is designed to have stakeholders consider the qualitative merits and demerits of possible interventions and treatments and to take into account the extent to which particular strategies will serve the unique needs of individual learners. Factors within this question relate to the perceived match of various interventions and treatments with the needs, values, and lifestyles of individual children and families. Consideration of these variables is the recognition that, independent of the reported research properties of specific methods, are qualitative variables that should be taken into account, including perceptions of how a child's personality, preferences, learning style, and unique parent and family circumstances might be suited to an intervention or treatment.

By their very nature, discussions of social validity factors connected to potential intervention and treatment methods are often lacking in traditional scientific traits. Nevertheless, even the most scientifically minded professionals who design programs for learners with ASD will attest that successful intervention and treatment involves consideration of both scientific and qualitative factors. Stakeholders connected to children and youth with ASD have different opinions and perspectives linked to their roles, experiences, attitudes, individual circumstances, and so forth. Social validity discussions among stakeholders provide an opportunity to discuss topics such as whether a particular intervention will facilitate a student's achievement of post-school goals, judgments of the practical and pragmatic skill attainment and related benefits associated with various methods and curricula, and quality-of-life factors allied with the use of particular methods.

Along these lines, social validity discussions are designed to accommodate variable voices among stakeholders regarding the perceived practical benefits of interventions and treatments. These conversations are not intended to supplant consideration of interventions and treatments based on their quantitative and empirical scientific qualities. Rather, this agenda is intended to broaden the vetting standards of possible interventions and treatments by combining quantitative and other objectively verified properties of methods with informal and qualitative considerations.
Also included in question 3 discussions are possible negative outcomes or side-effects associated with using a method, including health, monetary, and quality-of-life risks for a child and/or family. For example, a family that might be considering implementation of an intensive and longterm applied behavior analysis training program with a young child with autism should be assisted in considering the financial, time, and potential quality of life impact on a family associated with committing to such a program. These discussions also include consideration of what options would be excluded if a particular method were to be adopted. Obviously, stakeholders, including professionals and parents, have finite amounts of time and opportunities to work with children and youth with ASD. Adopting one intervention or treatment typically results in rejecting other options. Accordingly, objective evaluation of treatments and interventions requires that stakeholders carefully contrast and judge sideby-side alternative strategies, including the consequences of dropping one alternative in favor of another.

\section{FUNDAMENTAL EFFECTIVE-PRACTICE PROGRAM ELEMENTS FOR LEARNERS WITH ASD}

The successful education of students with ASD, it is nearly universally agreed, requires individualized programming based on effective methods implemented by well trained professionals. ASD authorities, parents, family members, and other stakeholders agree that positive educational outcomes for learners diagnosed with ASD happen only as a result of effective interventions, treatments, and related strategies (Lerman, Vorndran \& Addison, 2004; Zager \& Shamow, 2005). It also is clearly acknowledged that skilled and practiced professionals and carefully orchestrated home and school-support systems are needed to sustain positive outcomes (Fiedler, Simpson, \& Clark, 2007). Yet, there are few points of accord beyond general agreement that children and youth diagnosed with ASD should be educated using effective methods. As mentioned earlier, there are significant disagreements related to the meaning of an effective practice, and strident debates over which of the countless intervention and treatment options for students diagnosed with ASD have the best chance of bringing about maximally beneficial outcomes.

These disagreements are deep-rooted and show no signs of abating any time soon. Unquestionably, resolution of these significant effective-practice-related issues is challenging. Yet, this is such an important task that stakeholders must work to identify agreed-upon effectual strategies, curricula, and procedures. In this connection, three critical and foundational elements allied with use of effective practices and strategies with learners with ASD are discussed next. 
These fundamental components are offered as prerequisite groundwork upon which more refined application of effective interventions and treatments for learners with ASD can be layered.

\section{Critical Foundational Element 1: Qualified and Committed Educational Personnel}

Regrettably, the present dialogue related to using effective and scientific-based methodology with students with ASD has been woefully lacking in discussions of personnel. Unmistakably, even the most scientifically valid methods are only as effective as the individuals who use them. Without a doubt, classroom teachers and related-services professionals play crucial leadership roles in the selection and use of appropriate methods. To fully carry out their duties with competence, educators must individually craft suitable methods to suit the requirements of individual learners, systematically implement these tools with fidelity, methodically evaluate the impact of strategies, and make suitable program amendments as needed.

Further, we must take into account the professionals who must competently, consistently, and reliably apply supports and practices to fit individual students' needs.

Skilled and qualified teachers and program managers are sine qua non requirements of high-quality programs for students with ASD. Independent of delivery models, intervention and treatment strategies, and similar considerations, educators are the crucial leaders who direct and coordinate students' learning and program administration. In the end, these individuals are the ones who will primarily determine the outcomes for students.

This foundational element also recognizes that desired outcomes are closely linked to positive human relationships. Appropriate application of effective interventions and treatments with learners with ASD inherently involves interactions between learners and instructors. These person-to-person relationships transcend and interact with interventions and treatments. This principle applies to any instructional relationship and recognizes that methodologies don't operate independently of teachers.

Related to children and youth with ASD, this basic instructional principle is often overlooked or minimized. Some even argue that teachers should attempt to be mechanical in demeanor and persona in their instructional interactions with students with ASD and otherwise attempt to minimize displays of human behavior. This opinion is based on the mistaken assumption that children and youth with ASD are often uninterested in other people and learn best under conditions of neutral human involvement and face-to-face interaction. This claim thus implies that methodologies are most successful in facilitating skill and knowledge acquisition when teachers play neutral roles.
Without question, though, children and youth diagnosed with ASD make their most significant and enduring progress when they are able to build trusting and positive relationships with their teachers and when these constructive interpersonal relationships are interlinked to effective interventions and treatments. It would be difficult to find a teacher of students with ASD who will not support this position and who will not willingly offer illustrations of how interpersonal rapport and constructive relationships were the fuel that motivated students to respond most successfully to curricula and methods.

The notion that recognizing the importance of positive relationships between students and teachers and preparing teachers to leverage the strength of their human interactions with learners with ASD in no way suggests that teachers need not follow appropriate instructional protocol. Teachers must use effective-practice instructional methods, such as providing differential social reinforcement contingent upon specified behaviors, avoiding reinforcement of inappropriate behaviors with attention, subtly or unknowingly cueing students to make certain responses, and so forth. Gearing instructional equations to include effective practice methods as well as qualified personnel who are able to bring into play their human qualities to forge positive and trusting relationships with their students and enhance learning acknowledges that well trained and qualified teachers and support personnel are the predominant ingredient in successful programs for students with ASD.

Researchers (Darling-Hammond \& Youngs, 2002) have identified a direct relationship between educational outcomes of students and the characteristics of their teachers. Wayne and Youngs' (2003) observation that "both intuition and empirical research tell us that the achievement of school children depends substantially on the teachers they are assigned (p. 89)" This terse and candid statement applies to all learners, including those diagnosed with ASD. Yet, many programs for students with ASD undeniably are staffed by personnel who lack the knowledge and skills needed to teach children and youth with autism-connected disabilities effectively.

Without large-scale state and national programs to increase the pool of qualified educational personnel for learners with ASD, learners diagnosed with autism-related disabilities will fail to make optimal progress. Bluntly stated, effective-practice implementation and aggregate program improvement for children and youth with ASD will come about only as a result of having an adequate supply of competent, skilled teachers and other related-services personnel who understand students with ASD and are adept in applying individually crafted effective-practice interventions and treatments.

Discussion of the specific knowledge and skills that teachers of students with ASD should be required to have is 
beyond the reach of this article. In general, it includes a foundation of basic general and special education skills and knowledge, along with specialty skills in understanding essential characteristics of students with ASD, including social, communication, behavioral, and cognitive/learning. ASD-specific knowledge and skill in assessment and evaluation, effective-practice curricula and instructional methods, parent and family involvement, and collaboration with other professionals are also minimal requirements for teachers of students with ASD.

\section{Critical Foundational Element 2: Individualized Curricula and Programs That Address Salient Characteristics of ASD}

Children and youth with ASD display a range of characteristics and levels of functioning. Individuals diagnosed with Asperger disorder, for example, have needs that are significantly different from those of children with classic forms of ASD such as autistic disorder. Yet, across the spectrum, they share characteristics, principally, difficulty interacting normally with others. Across the ASD continuum, speech, language, and communication disabilities are present. Most individuals with ASD prefer routines, and many crave environmental consistency. Unusual and problematic behaviors are common, including atypical and strange interests and responses to sensory stimuli. Also, self-stimulatory and stereotypic behavior, and in some cases aggressive and selfinjurious behavior, may be present. Independent of their cognitive and language abilities and even if they exhibit highly developed and unique skills and abilities, students with ASD generally have learning difficulties. In spite of highly variable and idiosyncratic forms of ASD characteristics, individuals on the spectrum are linked by these notably heterogeneous and demanding features.

These traits make children and youth with ASD a markedly challenging group and, as such, they require individualized effective-practice-based programs engineered by qualified and experienced professionals. In this connection, the first step on the path to adopting effective practice methods is to ensure that stakeholders identify goals and objectives tied to the salient elements of ASD. That is to say, methodology considerations will be significant only if the targets for intervention are noteworthy correlates of ASD. One might logically argue that social interaction, communication, and behavioral and learning elements are the agreedupon central areas of need for children and youth diagnosed with ASD. It would follow that educators, parents, and other stakeholders would not have to be reminded that an effective program for students with ASD involves focusing on the elemental features of ASD. Although this line of thinking may be logical, it is painfully obvious that programs for far too many students with autism-related disabilities fail to address essential and core features of autism.

Individual and idiosyncratic student elements often seem to divert attention from the pivotal features of ASD. Informal inspection of learners' IEPs, for example, confirm that educational targets for students with autism-related disabilities frequently fall in areas outside the underlying features of ASD. Without attention to basic ASD building-block targets, the issues linked to effective interventions and treatments will be pointless and effective programs will be unattainable.

Essential targets include the core characteristics of ASD: social interaction; speech, language, and communication; and behavior. Additional targets include independent/daily living and community living skills, and academic, pre-academic, and functional academic skills. Other elements, too, characterize the countless permutations that comprise the particular and individualized forms of ASD in children and youth and, thus, students' individual programs must reflect this pattern. Nonetheless, the aforementioned areas comprise the basic components of ASD, so these should receive the major attention.

Children and youth with ASD have an irrefutable need for instruction and support in social and social interaction skills (Stichter \& Conroy, 2006). Given their social difficulties and social skill needs, any acceptable program for a learner with ASD would have to address this essential concern This takes into consideration the awareness that children and youth with ASD often are remarkably resistant to social training, and that schools are increasingly feeling the need to direct their time and attention to academic topics rather than matters that do not align with high-stakes testing.

All the same, because of the obvious need for social skill instruction and support among students with ASD and the knowledge that effective programs are available (Stichter, Randolph, Gage, \& Schmidt, 2007; Thiemann \& Kamps, 2008), clearly specified social targets should be included in these learners' programs. These targets also should reflect an awareness of various types of social skill deficits (Gresham, 1998), including acquisition deficits, social performance deficits, and fluency deficits.

Caldarella and Merrell (1997) identified the following general classes of social behavior that seem to be germane to the needs of students with ASD:

- Relationships with peers (e.g., prosocial skills)

- Self-control and self-management (e.g., rule compliance)

- Academically related social skills (e.g., awareness of classroom codes of behavior)

- Social compliance (e.g., cooperation with others)

- Social assertiveness (e.g., social initiation with peers) 
The diverse nature of these targets will require a range of social instruction and support tools, including direct skill instruction, consistent and ongoing coaching, peer development and support programs, and generalization training.

In a related fashion, students' speech, language and communication has to be recognized and translated into targets for intervention. As with other characteristics that form the ASD continuum, concerns range widely "from mutism to higher order social deficits" (Ogletree, 2008, p. 223).

The importance of communication and language skills to prognosis and post-school outcomes is profound (Ogletree, Oren, \& Fischer, 2007; Wetherby \& Prizant, 2000). Thus, appropriate objectives and targets in this domain are indispensable. Moreover, success in areas such as social skill development, behavior management, and acquisition and applied use of academic knowledge and skills are closely connected to communication and language development (Carr \& Durand, 1985).

Relative to facilitating appropriate communication targets, Ogletree, Saddler, and Bowers (1995) identified five critical variables:

1. Consideration of input of persons with autism and their families

2. Current and future communication needs of persons with autism

3. Emphasizing functional training related to intervention and treatment decisions

4. Factoring age-appropriateness when choosing goals, materials, and strategies, and

5. The strengths of persons with autism and their environments

Students with ASD also can be expected to have behavioral concerns, including stereotyped behavior, an assortment of atypical behaviors, traits that others judge as socially odd and improper, and, in some cases, aggressive and self-injurious behavior.

Thus, behavior and behavior management goals and objectives are essential program features for learners with ASD. The number of cost-effective and relatively easy-toimplement management options for students with ASD bodes well for success in this domain (Simpson \& Otten, 2005). Indeed, multifaceted support systems for individuals and for groups, founded on a clear understanding of relevant antecedents and motivational factors, used in a positive, consistent, and coordinated fashion, have consistently shown the capacity to yield success (Maag, 2004). Because medically based treatments may also be warranted, behavioral targets must be precisely identified and regularly monitored. Collaborative relationships characterized by ongoing information exchange and communication are essential.
Additional goal and objective targets include daily and independent living skills, aptitude and capacity to live and work independently in community settings, and academic, pre-academic, and functional academic skills. Community and independent living programs for adolescents and young adults and individuals with significant cognitive impairments are highly relevant to the needs of many children with ASD and individuals with so-called higher-functioning ASD. In addition to enhancing school success, these goals have been correlated positively with quality-of-life factors, family and community success, and overall acceptance by others (Kohler \& Field, 2003).

Academic skill targets for all groups on the ASD continuum should also be considered. A number of individuals with significant developmental disabilities and cognitive impairments are appropriate candidates for functional skill training in areas such as basic reading and math. Students with Asperger disorder and other forms of higher-functioning ASD typically receive most of their education in general education settings. They also are increasingly attending college and are aspiring to enter the workforce in technical and professional fields. Hence, their need for academic skills and knowledge is evident.

\section{Critical Foundational Element 3: Structured and Consistent Environmental Platforms for Application of Effective Practices}

Structured settings are a prerequisite condition for applying and evaluating treatments and interventions with the potential for use with learners with ASD. Structured environments provide physical and psychological organization for students through consistency and routines and by creating conditions that permit learners to anticipate task requirements and understand behavior and performance expectations. Without the foundation of structured settings, even the most robust methodologies will be inept and ineffectual, and clear-cut evaluation of their impact on goal and objective targets will not be possible.

A comparison that is equivalent to a structured setting for children and youth with ASD would be a surgery room with characteristics that meet customary medical standards set by an organization such as the American Medical Association. Within such a setting, a skilled surgeon should be able to apply his or her expertise to identified goals. Without an acceptable medical setting, however, even the most skilled surgeon will be unable to perform.

Creating structured settings for students with ASD as a foundation for applying individually crafted interventions and treatments is a fundamental and essential feature of a minimally effective program for children and youth with ASD. These conditions straightforwardly recognize that some basic factors bode well for every student with ASD 
and create environments that permit application of potentially utilitarian interventions and treatments. The Committee on Educational Interventions for Children with Autism (National Research Council, 2001) recognized the need for basic conditions in all classrooms and programs that serve young children with ASD by identifying the following basic characteristics:

\begin{abstract}
...early [age] entry into an intervention program; active engagement in intensive instructional programming for the equivalent of a full school day, including services that may be offered in different sites, for a minimum of five days a week with full-year programming; use of planned teaching opportunities, organized around relatively brief periods of time for the youngest children (e.g., 15-20-minute intervals); and sufficient amounts of adult attention in one-to-one or very small group instruction to meet individualized goals. (p. 6)
\end{abstract}

Additional markers of structured, predictable, and consistent classroom environments are clearly identified and enforced rules, unambiguous and reasonable expectations, resources that permit systematic monitoring of performance, and appropriate performance support. The recommendations of Brophy (1988) (albeit not intended specifically for students with ASD) are also applicable. He recommends that programs be crafted to recognize and support students' personal needs; create and maintain positive relationships among teachers, staff, and students; understand and address students' academic and related needs; use a variety of appropriate management methods; and are based on predictable routines and organization.

Given the physical and sensory needs of many children and youth with ASD, appropriate attention should be given to physical settings by providing suitable lighting, sound systems, heating and cooling, storage, and so forth. Ganz (2007) recommends visual support systems for learners with ASD related to their perceived visual processing strengths and weaknesses in auditory processing, memory, and communication. She also notes that visual support tools can facilitate students' independence and reduce their need for adult prompts and correction feedback.

Similarly, proponents of the TEACCH model (Schopler, Mesibov, \& Hearsey, 1995) recommend use of visual supports and visual boundaries to organize classrooms, physical borders such as room dividers and tape on the floor to identify classroom areas for designated activities, room dividers, and prudent selection and placement of materials to reduce distractions. Color-coding and organizing classroom materials using pictures and labels are additional suggestions that they and others offer for organizing environments (Scheuermann \& Webber, 2002).

Empirical scientific support for many of the specific structuring tools commonly recommended for learners with
ASD is lacking. Nevertheless, efforts to confirm efficacy of these tools is increasing, and various purported structuring methods are being scientifically tested. Thus, for instance, evidence is mounting that visual supports are beneficial for many students (Ganz, 2007). The face validity of routines, organized schedules, carefully crafted classroom physical arrangements, and so forth are obvious. As a result, there is general acknowledgement of the benefits of structured learning environments for learners with ASD, despite a less than fully settled scientific validation landscape.

To be sure, children and youth with ASD require structure and organization to be able to learn and develop. But it is also increasingly clear that, while a necessary prerequisite for an effective program, the mere presence of structure and organization will not be sufficient to ensure that students with ASD receive an appropriate education. Structure and organization are merely elemental and preconditions needed to pave the way for effective practices that can address specific student needs. Without doubt, effective practices cannot be implemented effectively in settings that lack structure and organization. In the same fashion, structure and organization without the additional use of individually crafted interventions and treatments will be insufficient to achieve individual student outcomes.

\section{FINAL THOUGHTS}

Basic steps are needed to begin to clarify and use maximally effective methods with students with ASD. Notwithstanding agreement that students with ASD require effective methods implemented by qualified professionals, there are myriad unresolved issues and few points of accord relative to identifying and using effectual interventions and treatments. This state of affairs is particularly disquieting because students' outcomes are visibly coupled with prudent intervention and treatment choices. The harsh reality faced by all too many students, families, and communities is that numerous learners with ASD currently are not receiving an education based on effective methods, and that not all educators who work with these learners are adequately prepared to use strategies, curricula, and procedures associated with the best outcomes.

Acknowledging the flawed and unsettled state of affairs relative to educating students with ASD is an important first step toward improving conditions by beginning the challenging process of identifying and consistently implementing the most utilitarian and objectively supported practices. Reform will not be easy. It will require acknowledgement by professionals, parents, family members, and other stakeholders in the field that we must collectively begin working to identify agreed-upon foundational elements and features of effective programs for children and youth with ASD. 
These vital and rudimentary factors and features comprise the essential cornerstone of programs for students with ASD.

A process is also also needed for involving stakeholders in systematic courses of action leading to the selection, implementation, and evaluation of suitable goals and objectives and corresponding methods for individual students with ASD. Selected interventions and treatments must be those that have the best chance of producing the desired results; thus, systematic programs have to be designed to support this vetting process. This article was written as one means of stimulating dialogue, leading to adoption of the practices that will best serve the needs of children with ASD and their families.

\section{REFERENCES}

Biklen, D. (1993). Communication unbound: How facilitated communication is challenging traditional views of autism and ability/disability. New York: Teachers College Press.

Brophy, J. (1988). Educating teachers about managing classrooms and students. Teaching and Teacher Education, 4(1), 1-18.

Caldarella, P., \& Merrell, K. (1997). Common dimensions of social skills of children and adolescents: A taxonomy of positive social behaviors. School Psychology Review, 26, 265-279.

Carr, E., \& Durand, V.M. (1985). Reducing behavior problems through functional communication training. Journal of Applied Behavior Analysis, 18, 111-126.

Centers for Disease Control and Prevention. (2008). Autism information center. Retrieved June 9, 2008, from http://www.cdc.gov/ncbddd/autism/

Christie, K. (2008). Can those tweens and teens read yet?. Phi Delta Kappan, 89(9), 629-30, 703.

Council for Exceptional Children, Smart Brief. (2008) New hope for autism. Retrieved May 5, 2008, from http://www.smartbrief.com/

Darling-Hammond, L., \& Youngs, P. (2002). Defining "highly qualified teacher"; what does "scientifically-based research" actually tell us? Educational Researcher, 31(9), 13-25.

deBoer, S. (2007). How to do discrete trial training. Austin, TX: ProEd.

Fiedler, C., Simpson, R., \& Clark, D. (2007). Parents and families of children with disabilities: Effective school-based support services. Upper Saddle River, NJ: Pearson-Merrill/Prentice Hall.

Freeman, B.J. (1997). Guidelines for evaluating intervention programs for children with autism. Journal of Autism and Developmental Disorders, 27(6), 641-651.

Ganz, J. (2007). Classroom structuring methods and strategies for children and youth with autism spectrum disorders. Exceptionality, 15(4), 249-260.

Gresham, F.M. (1998). Social skills training: Should we raze, remodel or rebuild? Behavioral Disorders, 24, 19-25.

Gresham, F., Beebe-Frankenberger, M., \& MacMillan, D. (1999). A selective review of treatments for children with autism: Descriptive and methodological considerations. School Psychology Review, 28(4), 559-575.

Guernsey, D. (2006, August 1). Autism's angels. Town and Country, pp. 90-102.
Hardy, Q. (2008, May 5). New hope for autism. Forbes, p. 54.

Heflin, J., \& Simpson, R. (1998a). Interventions for children and youth with autism: Prudent choices in a world of exaggerated claims and empty promises. Part 1: Intervention and treatment option review. Focus on Autism and Other Developmental Disabilities, 13(4), 194-211.

Heflin, J., \& Simpson, R. (1998b). Interventions for children and youth with autism: Prudent choices in a world of exaggerated claims and empty promises. Part 11: Legal policy analysis and recommendations for selecting interventions and treatments. Focus on Autism and Other Developmental Disabilities, 13(4), 212-220.

Institute of Education Sciences, U.S. Department of Education Institute of Educational Sciences, What Works Clearinghouse. (2008). Retrieved June 30, 2008, from http://ies.ed.gov/ncee/wwc/

Iovannone, R., Dunlap, G., Huber, H., Kincaid, D. (2003). Effective educational practices for students with autism spectrum disorders. Focus on Autism and Other Developmental Disabilities, 18, $150-165$.

Kalb, C. (2005, February 28). When does autism start? Newsweek, pp. 45-53.

Kalb, C. (2008, March 24). Mysteries and complications; Autism is everywhere once again. Separating fact from fear as the courts and Hollywood wade in. Newsweek, pp. 64-65.

Koegel, L., Carter, C., \& Koegel, R. (2003). Teaching children with autism self-initiations as a pivotal response. Topics in Language Disorders, 23(2), 134-145.

Kohler, P.D., \& Field, S. (2003). Transition-focused education: Foundation for the future. Journal of Special Education, 37(3), 174-183.

Lerman, D., Vorndran, L., \& Addison, L. (2004). Preparing teachers in evidence-based practices for young children with autism. School Psychology Review, 33(4), 510-526.

Lotter, V. (1966). Epidemiology of autistic conditions in young children. Social Psychiatry, 4, 263-277.

Maag, J. (2004). Behavior management: From theoretical implications to practical applications. Belmont, CA: Wadsworth/Thomson..

National Research Council. (2001). Educating children with autism. Washington, DC: National Academy Press.

No Child Left Behind Act. (2001) 20 U.S.C. $70 \S 6301$ et seq.

Odom, S., Brantinger, E., Gersten, R., Horner, R., Thompson, B., \& Harris, K. (2005). Research in special education: Scientific methods and evidence-based practices. Exceptional Children, 7l(2), 137-148.

Ogletree, B. (2008). The communicative context of autism. In R. Simpson \& B. Myles (Eds.), Educating children and youth with autism: Strategies for effective practice (pp. 223-265). Austin, TX: ProEd.

Ogletree, B., Oren, T., \& Fischer, M. (2007). Examining effective intervention practices for communication impairment in autism spectrum disorder. Exceptionality, 15(4), 233-248.

Ogletree, B., Saddler, Y., \& Bowers, L. (1995). Speech pathology. In B. Thyer \& N.P. Kropf (Eds.), Developmental disabilities: A handbook for interdisciplinary practice (pp. 217-233). Cambridge, MA: Brookline.

Romanczyk, R., \& Gillis, J. (2005). Treatment approaches for autism: Evaluating options and making informed choices. In D. Zager (Ed.), Autism spectrum disorders: Identification, education and treatment (pp. 515-535). Mahwah, NJ : Lawrence Erlbaum.

Scheuermann, B., \& Webber, J. (2002). Autism: Teaching does make a difference. Belmont, CA: Wadsworth. 
Schopler, E., Mesibov, G. B., \& Hearsey, K. (1995). Structured teaching in the TEACCH system. In E. Schopler \& G. B. Mesibov (Eds.), Learning and cognition in autism (pp. 243-267). New York: Plenum.

Simpson, R.L. (2005). Evidence-based practices and students with autism spectrum disorders. Focus on Autism and Other Developmental Disabilities, 20(3), 140-149.

Simpson, R., deBoer, Griswold, D., Myles, B., Byrd, S., Ganz, J., et al. (2005). Autism spectrum disorders: Interventions and treatments for children and youth. Thousand Oaks, CA: Corwin Press.

Simpson, R., McKee, M., Teeter, D., \& Beytien, A. (2007). Evidencebased methods for children and youth with autism spectrum disorders: Stakeholder issues and perspectives. Exceptionality, 15(4), 203-217.

Simpson, R., \& Myles, B. (2008). Educating children and youth with autism: Strategies for effective practice. Austin, TX: Pro-Ed.

Simpson, R., \& Myles, B. (1995). Facilitated communication and children with disabilities: An enigma in search of a perspective. Focus on Exceptional Children, 27(9), 1-15.

Simpson, R., Myles, B., \& Ganz, J. (2008). Efficacious interventions and treatments for learners with autism spectrum disorders. In R. Simpson \& B. Myles (Eds.), Educating children and youth with autism: Strategies for effective practice (pp. 477-512. Austin, TX: Pro-Ed.

Simpson, R., \& Otten, K. (2005). Structuring behavior management strategies and building social competence. In D. Zager (Ed.), Autism spectrum disorders: Identification, education and treatment (pp. 367-394). Mahwah, NJ: Lawrence Erlbaum.

Stichter, J. \& Conroy, M. (2006). How to teach social skills and plan for peer social interactions. Austin, TX: Pro-Ed Publishers.

Stichter, J., Randolph, J., Gage, N., \& Schmidt, C. (2007). A review of recommended social competency programs for students with autism spectrum disorders. Exceptionality, 15(4), 219-232.

Strain, P. S., \& Hoyson, M. (2000). The need for longitudinal, intensive social skill intervention: LEAP follow-up outcomes for children with autism. Topics in Early Childhood Special Education, 20(2), $116-122$.

Sturmey, P. (2008). How to teach verbal behavior. Austin, TX: Pro-Ed.

Thiemann, K., \& Kamps, D. (2008). Promoting social-communicative competence of children with autism in integrated environments. In R. Simpson \& B. Myles (Eds.), Educating children and youth with autism: Strategies for effective practice (pp. 267-298). Austin, TX: Pro-Ed.

Volkmar, F., Cook, E., \& Pomeroy, J. (1999). Practice parameters for the assessment and treatment of children, adolescents and adults with autism and pervasive developmental disorders. Journal of the American Academy of Child and Adolescent Psychiatry, 38(12), 32S-54S.

Wallis, C. (2006, May 15). Inside the autistic mind. Time, pp. 43-51.
Waly, M., Olteanu, H., Banerjee, R., Choi, S., Mason, J., Parker, B., et al. (2004). Activation of methionine synthase by insulin-like grown factor-1 and dopamine: A target for neurodevelopmental toxins and thimerisal. Molecular Psychiatry, 9, 358-370.

Wayne, A.J., \& Youngs, P. (2003). Teacher characteristics and student academic achievement: A review. Review of Educational Research, 73(1), 89-122.

Wetherby, A.M., \& Prizant, B.M. (Eds.) (2000). Autism spectrum disorders: A developmental, transactional perspective. Baltimore: Paul Brookes Publishing Co.

Wheeler, D., Jacobson, J., Paglieri, R., \& Schwartz, A. (1993). An experimental assessment of facilitated assessment. Mental Retardation, 31(1), 49-60.

Young, H., Grier, D., \& Grier, M. (2008). Thimerosal exposure in infants and neurodevelopmental disorders: An assessment of computerized medical records in the Vaccine Safety Datalink. Journal of Neurological Sciences, 271(1-2), 110-118.

Zager, D., \& Shamow, N. (2005). Teaching students with autism spectrum disorders. In D. Zager (Ed.), Autism spectrum disorders: Identification, education and treatment (pp. 295-326). Mahwah, NJ: Lawrence Erlbaum.

\section{STATEMENT OF OWNERSHIP, MANAGEMENT AND CIRCULATION}

Date of Filing: November 24, 2008

Title of Publication: Focus on Exceptional Children

Frequency of Issue: Monthly (except June, July \& August)

Location of Known Office of Publication: 9101 E. Kenyon Ave, Suite 2200, Denver, $\mathrm{CO} 80237$

Location of Headquarters of Publisher: 9101 E. Kenyon Ave., Suite 2200, Denver, CO 80237

Name and Address of Publisher, Editor, and Managing Editor: Stanley F. Love, 9101 E. Kenyon Ave., Suite 2200, Denver, CO 80237

Owner: Love Publishing Company

Extent and Nature of Circulation: Average No. Copies Single Issue World Wide Academic

Each Issue During

Total No. Copies Printed Preceding 12 Months Nearest

Paid Circulation

Sales through Dealers, etc.

Mail Subscriptions

Other Classes Mailed Through USPS

Total Paid Circulation

Free Distribution Outside the Mail

Free Distribution

Total Distribution

Office Use and Left Over

Total 1300

Filing Date 1300

$\begin{array}{rr}46 & 42 \\ 1094 & 1094 \\ 45 & 44 \\ 1185 & 1180 \\ 10 & 15 \\ 75 & 65 \\ 1270 & 1260 \\ 30 & 40 \\ 1300 & 1300\end{array}$

I certify that the statements made by me above are correct and complete. 


\section{new books}

\section{Educating Children and Youth with Autism- Second Edition \\ Strategies for Effective Practice \\ Richard L. Simpson, Brenda Smith Myles}

Autism spectrum disorders span a wide range of complex characteristics, developmental disabilities, behaviors, and functioning levels, from mild to severe. This diverse range contributes to the difficulty in designing effective educational and treatment programs, as each individual has specific needs. Educating Children and Youth with AutismSecond Edition is an educator-oriented guide dedicated to providing professionals and educators with current information, guidelines, and resources on ASD.

538 pages, O2008, ISBN 978-4164-02101-9

\section{Preschool Education Programs for Children with Autism-Third Edition}

\section{Jan S. Handleman, Sandra L. Harris}

Since the first two editions of Preschool Education Programs (1994, 2001), more exciting advances, particularly Applied Behavior Analysis (ABA), have arisen to benefit the special education of youngsters in school. Contributing to this 12-chapter edition are 10 scholar programs (Alpine Learning Center; ASCENT; Autism Center at the University of Washington; CABAS Program; Children's Unit at SUNY Binghamton; Douglass Developmental Disabilities Center; Groden Center; LEAP Program; Summit Academy Sussex Consortium; and Valley Program), answering a common set of questions concerning the treatment of very young children with Autism Spectrum Disorders, using a range of ABA technology. This book addresses educational settings including public, private, and university-based programs in America. It is an especially valuable resource for parents, professionals, and administrators who are in the process of developing programs for the preschool student.

381 pages, (2008, ISBN 978-1-4164-0257-2

\section{Language and Autism}

Applied Behavior Analysis, Evidence, and Practice Adrienne Fitzer, Peter Sturmey

This book is intended to provide clear guidance to practitioners in a concise format. The proposed volume is an edited work consisting of 12 chapters. Each of the chapters includes a final section on practitioner recommendations. The first two chapters include behavioral theory of language acquisition; and the efficacy of behavioral and other approaches commonly used interventions as applied to language. The next group of chapters addresses common targets, such as requesting, elaborated language use, reading and writing, and non-social interventions for language acquisition. The next chapters address commonly used behavioral interventions, functional communication training, and incidental teaching. The final chapter addresses decreasing inappropriate language. This volume will provide the reader with a concise overview of applied behavioral interventions for language in people with autism spectrum disorders.

175 pages, (O2009, ISBN 978-1-4164-0370 


\section{professional update}

Teacher Education Division, (CEC)

November 5-8, 2008

Dallas, Texas

$\begin{array}{ll}\text { Contact: } & \text { www.tedcec.org } \\ & 940-565-3583\end{array}$

American Speech-Language-Hearing Association, Annual Conference

November 20-22, 2008

Chicago, Illinois

Contact: www.asha.org

email: actioncenter@asha.org

800-638-8255

\section{TASH Annual Conference}

December 3-6, 2008

Nashville, Tennessee

Contact: www.tash.org

email: THC@ housingregistration.com

888-221-9425
National Association of School Psychologists

February 24-28, 2009

Boston, Massachusetts

$\begin{array}{ll}\text { Contact: } & \text { www.nasponline.org } \\ & 866-331-6277\end{array}$

Learning Disabilities Association, Annual International Conference

February 25-28, 2009

Salt Lake City, Utah

Contact: www.ldanatl.org

412-341-1515 